Article

\title{
Government Reward-Penalty Mechanism in Dual-Channel Closed-Loop Supply Chain
}

\author{
Haitao Chen ${ }^{1,+}$, Zhaohui Dong ${ }^{1, *(1)}$ and Gendao $\mathrm{Li}^{2,+}$ \\ 1 School of Management, Jilin University, Changchun 130015, China; chenht@jlu.edu.cn \\ 2 School of Economics and Management, Changchun University of Science and Technology, \\ Changchun 130000, China; gendaoli@cust.edu.cn \\ * Correspondence: dongzh18@mails.jlu.edu.cn \\ + These authors contributed equally to this work.
}

Received: 17 August 2020; Accepted: 12 October 2020; Published: 17 October 2020

\begin{abstract}
This study establishs a dual channel closed-loop supply chain (CLSC) model under a government-penalty mechanism (RPM) consisting a dual-channel manufacturer, a retailer, and the government. We consider a Stackelberg game between the manufacturer and the retailer, and the government rewards or punishes manufacturers on the basis of the collection rate of used products. This paper analyzes the influence of government RPM on the optimal decisions, the relationship between the two sales channels, and the total social welfare of the supply chain system. We find that the government RPM can improve the stability of the dual-channel supply chain and the collection rate of the used products. Moreover, we are the first to provide a method of deriving the optimal government RPM through a numerical example.
\end{abstract}

Keywords: dual channel; closed-loop supply chain; reward-penalty mechanism; game theory; pricing strategies

\section{Introduction}

In the last decade, resource shortages and environmental problems have received more and more attention in both academia and industry. With the rapid technological development, the replacement of electronic products is very fast, with more and more different models, which makes the used products difficult to deal with, causing a lot of waste of resources and pollution. Waste electrical and electronic equipment (WEEE), such as LCD TVs, mobile phones, and so on, contains a lot of toxic chemicals, which pollute land and groundwater and threaten human health and even survival. In order to solve the problems of resources and pollution, the concept of the extended warranty period (EPR) has been proposed to recycle the used products and incentivize the manufacturer to fulfill their social responsibility. EPR policies indicate that the producer's responsibility not only refers to production, but should extend to the entire product life cycle, including product disposal, recycling, and remanufacturing processes. Many governments worldwide explore various forms of EPR polices with financial intervention. For instance, Japan has implemented the "Household Appliance Recycling Act" since 2002. Furthermore, the European Union (EU) enacted the Electronic Equipment Directive in 2003, which emphasizes penalties. In 2003, the Cailifornia government provided manufacturers of electronic products with pre-payments to promote remanufacturing and waste recycling, and intervened in the manufacturing through taxation; in addition, the recyclers were given subsidies for recycling of waste products. Based the above policies, China issued the Waste Electrical and Electronic Equipment Recycling Management Regulation in 2011, forcing manufacturers to collect used products actively. These polices are all penalty-based, which means that manufacturers will be penalized if they fail to achieve the recycling or reuse targets set by governments. However, 
this may motivate companies to just recycle the minimum required amount without any incentive to do more.

Recently, some researchers proposed a reward-penalty mechanism (RPM) [1,2], which combines penalty and rewards. If the actual quantity of recycling is higher than the target recycling quantity, the government will reward the manufactures; otherwise, the government penalizes the manufactures, which can urge enterprises to participate in recycling and remanufacturing activities of used products. Compared to other government policies, the RPM can save government expenditure and is more flexible. However, the current discussion is based on a traditional business setting, where only the physical channel is considered. Nowadays, e-commerce is playing an important role in businesses, and is changing the traditional supply chain structure [3]. The online channel provides manufactures the opportunity to directly face the market and consumers. For instance, consumers can purchase all Apple products through the online store. Huawei has established VMall.com to sell its products online. Meanwhile, consumers who are unwilling to purchase online can buy the products through an authorized physical store offline. Establishing the dual-channel pattern model can shorten the distance between manufacturing and market demand, which can also enlarge the market demand through a service improvement. Moreover, dual channels can also help in waste collection and the sale of remanufactured/recycled products. Some manufactures have begun to collect used products to solve the concerns of resource consumption and environmental pollution using different channels. In Huawei's VMall platform, it provides a "trade-in" program, which encourages consumers to return their used products when purchasing new ones by rewarding with discounts or credits. Meanwhile, some third-party companies are also undertaking the tasks of recycling used Huawei phones, such as LE RECYCLING, JD, and so on. Authorized offline stores of Huawei also collect used products and sell the products to the consumers who favor physical stores. Similarly, Apple has also established a dual-channel closed-loop supply chain to sell new products and collect used ones through online and offline stores.

Due to the prevalence of dual-channel closed-loop supply chains, it is worth investigating the effects of policies in this new setting. However, it is still unclear what the impact of the RPM on dual-channel closed-loop supply chains is. In this paper, we will explore how the RPM scheme affects the decisions of supply chain members and social welfare, as well as how the government should design the RPM scheme. In particular, we aim to answer the following questions:

(1) How does the government RPM scheme affect the optimal decisions of the supply chain members of the dual-channel supply chain?

(2) When should the manufacturer develop dual channels to sell products? How does the government RPM affect the relationship between the online channel and retailer channel?

(3) How does the government set the parameters of RPMs to maximize the total social welfare?

This paper has four contributions to the literature. First, to the best of our knowledge, this paper is the first to investigate the government RPM in the dual-channel closed-loop supply chain (CLSC), and the dual channel supply is prevalent in practice. Second, we analyze the impact of government financial intervention, and we are surprised to find that it can relieve the conflict of the online and offline channels. Third, we study the impact of the government RPM's intensity on supply chain decisions, and find that as the government RPM intensity increases, the online price, retailer price, and wholesale price decrease and the collection rate increases. Fourth, we provide a method for the government to set the optimal RPM to maximize social welfare.

The remainder of the paper is organized as follows. In the next section, we provide a literature review related our research. We describe the problem and develop our model in Section 3. Section 4 solves the equilibrium decisions in the dual-channel CLSC. We provide the analysis of the impact of the government RPM on the total social welfare in Section 5. How the government sets the optimal RPM to maximize the social welfare is analyzed in Section 6. Section 7 summarizes our main findings and implications, and outlines the limitations of our work and directions for future research. 


\section{Literature Review}

Our work is related to three streams of literature. The first stream is about dual-channel supply chains, the second one is about CLSC management, and the last one is about the impact of governmental financial intervention on the decisions of CLSC supply chains.

Previous studies on the dual-channel supply chain (DCSC) mainly focus on pricing strategies, channel conflicts, and coordinate mechanisms. Chiang et al. (2003) [4] study the role of direct marketing on the dual-channel supply chain. They developed a pricing model between a manufacturer and an independent retailer, and found that indirect marketing improved all the supply chain member's profits. However, to the retailer, the introduction of indirect marketing can decrease the wholesale price set by the manufacture whilst increasing the whole market demand, which indicates the channel conflict between the online manufacturer and the offline retailer. Later, Huang and Swamianathan (2009) [5] investigated the optimal pricing strategies in DCSCs based on a deterministic demand model where the channel demands depend on the sales price, which is widely accepted by supply chain researchers. Tsay and Agrawal (2004) [6] constructed a model to capture the key attributes of a DCSC and proposed several ways to resolve channel conflict. Based on the above work, Dumrongsiri et al. (2008) [7] considered a DCSC with demand impacted by both sales prices and service quality. Then, Chen et al. (2012) [8] used a Stackelberg game model to study the pricing strategies and coordination mechanism between a dual-channel manufacturer and an offline retailer, where the manufacturer is the leader and the retailer is the follower. They find that two-part tariff and revenue sharing contracts can coordinate the dual-channel supply chain. Xu et al. (2014) [9] studied the risk attitudes between the manufacturer and the retailer that can affect the supply chain members' optimal decisions. They compared the risk-decentralized and centralized supply chain system under the mean-variance model, and found that the competition will decrease the supply chain efficiency. They established a dual-channel coordinating contract under a mean variance model to avoid risk. The previous literature proposes a lot of solutions for the dual-channel coordination mechanism to solve channel conflict, such as channel priority policy, service quality and decisions, complementary products, and so on [3,10-12]. However, the above literature mainly discusses the dual-channel construction, coordinate mechanism of channel conflict, and pricing strategies in the forward supply chain without considering the reverse supply chain.

The stream of literature about closed-loop supply chains focuses mainly on optimal decisions in both forward and reverse supply chains to improve the environmental performance and the profits of the supply chain members. A number of analyses have identified which player in the supply chain is the most efficient in collecting used products for the manufacturer [13]. One of the well-known studies was developed by Savaskan et al. (2004) [14], which compares three options of the manufacturer: manufacturer collections, retailer collections, and third-party collections. They find that ceteris paribus, the player who is closer to the customer, such as the retailer, is the most effective collector. In addition, they show that simple coordination mechanisms can be designed such that the collection effort of the retailer and the supply chain profits are attained at the same level as in a centrally coordinated system. Savaskan and Van (2006) [15] further extend the model to include competition among retailers and show that the manufacturer should entrust the collection activities of used products to the retailers under certain conditions. Ferrer and Swaminathan (2006) [16] study the decisions between the retailer and the manufacturer and their Nash equilibrium in the duopoly environment. They find that the remanufacturing activities are profitable for the manufacturer by reducing the unit cost of production from the recycled products. Based on the above closed-loop model and collecting modes, some researchers have studied the reward policy to improve the collection efficiency and the profits of the whole supply chain system. For instance, Saha et al. (2016) [17] established a dual-channel supply chain model to study the system performance, pricing strategies, and remanufacturing policies of the supply chain members. They proposed a three-way discount mechanism for the manufacturer to incentivize the efficiency of the reward-driven supply chain in the dual-channel setting. Then, the research was expanded to the incentive strategies, revenue sharing, 
collection policies, and coordination mechanism between the manufacturer and the retailer [18-21]. However, this literature does not discuss how government intervention influences the pricing strategies, coordination mechanism, and collection activities of a supply chain system, which is the main focus of this paper. We will discuss the most efficient collection mode, the manufacturer collection model, and the third-party collection model under the government RPM scheme.

The last stream of literature is about the effects of government intervention on the CLSC members. Government also plays an important role in coordinating the supply chain members and improving the performance of collection activities to ease environment problems [22]. Aksen et al. (2009) [10] developed two bilevel programming models to guide the government to choose the appropriate mode to subsidize manufacturers, and to establish companies' subsidization agreement with the government, who imposes a minimum collection rate on cores. Heydari et al. (2017) [23] explored the government's role in reverse and closed-loop chain coordination. They compared the effects of different government interventions on the supply chain members' decisions, and also compared tax exemption and subsidies to the manufacturer and the retailer, respectively. They found that government intervention for the manufacturer is more effective and economic than for the retailer. In addition, they also concluded that the government subsidy is more feasible than the government tax exemption. The government intervention improves the profits and performance of the supply chain; meanwhile, the new product price for the customer is lower than the condition without government intervention, which indicates that it also benefits the consumers. Ma et al. (2013) [24] consider the government subsidy from the customer side, which means that when the customer purchases the products, they can receive the subsidy paid by the government. This can improve the product quantity and market demand. They find that the government customer subsidy can improve the scale of the supply chain and the profits of all the supply members, and benefits the costumer. Zhang et al. (2018) [2] studied the government RPM based on dynamic game theory and principle-agent theory. They proposed three game models, two competitive manufacturers, and a recycler without any RPM, with only a carbon emission RPM or the government collection RPM and carbon emission RPM simultaneously. They found that the carbon emission RPM decreases supply chain performance and collection quantity; meanwhile, the intensity of the government collection RPM increases the supply chain's profit, the members' profits, and the collection quantity. Therefore, they advise that the government should decrease the carbon emission RPM and increase the collection RPM appropriately in order to improve the environmental performance. Wang et al. (2019) [25] compared the decisions of supply members in different power structures under a government reward-penalty mechanism. They found that the member that has more power in the supply chain always bears more responsibility with respect to the government reward-penalty mechanism. The above research mainly focuses on the simplest supply chain structure with one channel. Differently from the above, our work focuses on the model of a dual-channel closed-loop supply chain and the study of the impact of a government RPM.

From the review of the literature, we can see that although the government RPM's influences on collection activities have been extensively studied, how the government RPM influences the dual-channel closed-loop supply chain is not clear. In addition, the existing literature does not discuss how the government should optimize the RPM scheme. To the best of our knowledge, this is the first work to explore the impact of a government RPM on a dual-channel supply chain and to provide a method of obtaining the optimal RPM settings for the government.

\section{Problem Description and Model Setup}

We consider a dual-channel closed-loop supply chain, as depicted in Figure 1. The supply chain consists of one manufacturer and one retailer. The manufacturer produces new products with unit cost $c$, and sells the product through two channels, the direct channel at price $p_{1}$ and the retailer channel at wholesale price $w$. The retailer then sells the product at price $p_{2}$ to customers. The manufacturer can achieve residual value $s$ of the used products from consumers $[1,15,26]$. Meanwhile, the government 
will implement an RPM scheme for the individual manufacturer according to its collection rate of the used products from consumers, which is consistent with Wang et al. [25].

Following Huang and Swaminathan (2009) [5], Xu et al. (2014) [9], and Aksen et al. (2009) [10], we assume that the corresponding market demand functions for the manufacturer and the retailer are expressed as $d_{1}=\alpha a-b_{1} p_{1}+r p_{2}$ and $d_{2}=(1-\alpha) a-p_{2} b_{1}+r p_{1}$, where $d_{1}$ denotes the online market demand, whilst $d_{2}$ denotes the offline market channel market demand, $a$ is the potential market size, and $\alpha$ is consumers' loyalty to online channel; $b_{1}$ denotes the price elasticity for the online price and $r$ represents the degree to which the products sold through two channels are fungible. We assume $b_{1}>r$, which indicates that the effect of ownership price is greater than the effect of cross-price.

We only consider the scenario of the manufacturer collecting model. It has been proven that the direct collection model is the most profitable and efficient for the supply chain compared to entrusting third parties or retailers to collect used products. In practice, many companies have developed online platforms to collect used products from consumers, such as trade-in programs on Apple's and Huawei's websites. We denote the collection rate $\tau$, which indicates the effort of the manufacturer on the reverse channel. It will incur the $\operatorname{cost} C(\tau)=\frac{1}{2} k \tau^{2}$ for the manufacturer to collect used products, where $k$ denotes a scaling parameter. We assume that the used product is at the end of the product life cycle for the consumers, and the manufacturer can extract the valuable components from the recycled products, which can be used for remanufacturing. The used product collection function can be expressed as $\tau\left(d_{1}+d_{2}\right)$, which corresponds to the function used by Xie et al. (2018) [20] and Savaskan et al. (2004) [14].

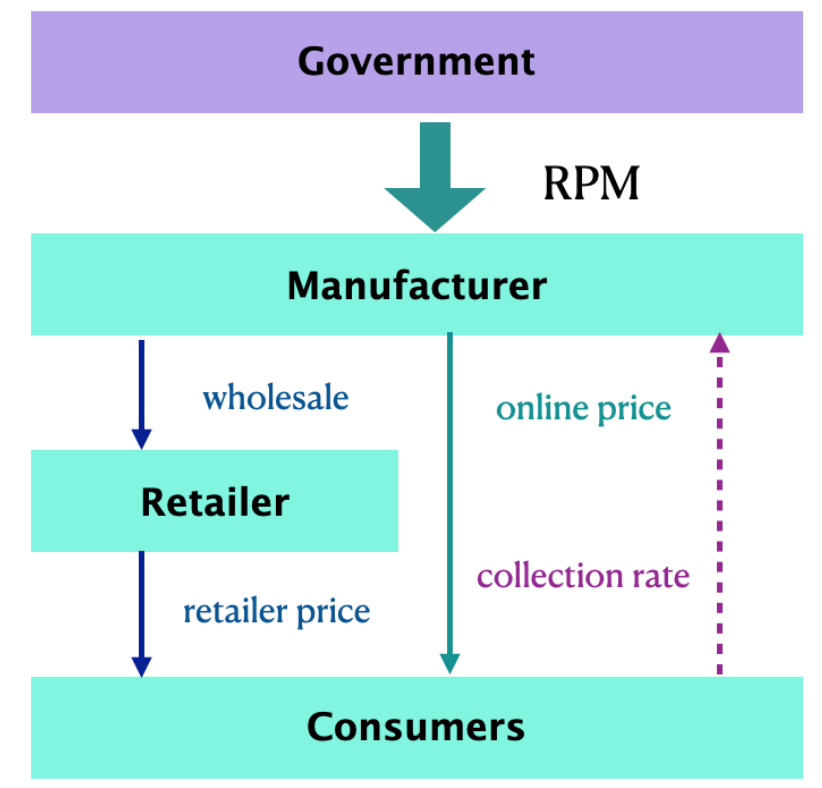

Figure 1. Manufacturer collection model with government reward-penalty mechanism (RPM).

The government implements an RPM scheme that requires a target collection rate $\tau_{0}$ to recycle/remanufacture. If the real collection rate is below the threshold, the manufacturer will be penalized at $m\left(\tau_{0}-\tau\right)$, while if above the threshold, the manufacturer will be awarded at $m\left(\tau-\tau_{0}\right)$. We name $m$ the intensity of the government RPM.

We assume that there is a Stackelberg game between the manufacturer and the retailer. The decision process is as follows: (1) The government decides the recycling target and RPM intensity, then (2) the manufacturer determines its online sales price $p_{1}$, wholesale price $w$, and the effort of collection $\tau$. (3) Then, the retailer purchases new products at wholesale $w$ from the manufacturer, and sells the products at price $p_{2}$ to customers. In our model, we assume that all members are risk-neutral, without regard to risk preference or risk aversion. Their targets are to earn the maximum profits. The related parameters are shown in Table 1. 
Table 1. Model parameters.

\begin{tabular}{cl}
\hline Symbol & Description \\
\hline$c$ & unit cost of production \\
$s$ & the residual value of collected used products \\
$r$ & the cross-price sensitivity \\
$b_{1}$ & the price-sensitive coefficient of the market demand \\
$\alpha$ & the coefficient of costumer loyalty to the online channel \\
$d_{1}$ & the online channel market demand \\
$d_{2}$ & the offline channel market demand \\
$a$ & the potential demand of the market, if the products are free \\
$k$ & the scaling parameter corresponding to the cost structure \\
$m$ & reward-penalty intensity set by government for the manufacturer \\
$\tau_{0}$ & target collection quantity set by government for the manufacture \\
$p_{1}$ & the online selling price set by the manufacture \\
$p_{2}$ & the offline selling price set by the retailer \\
$\tau$ & the collection rate of the used products \\
$w$ & wholesale set by manufacture to retailer \\
$\pi_{m}$ & The manufacturer's profit \\
$\pi_{r}$ & The retailer's profit \\
\hline
\end{tabular}

Meanwhile, the superscript "**" denotes the optimal value of the variables and expressions, and the superscripts " $M D$ " and " $M T$ " respectively represent the parameters corresponding to the manufacturer collection model and the third-party collection model.

\section{Model Analysis}

We first consider the manufacturer collection model in a Stackelberg game framework between a dual-channel manufacturer and an offline retailer. Given the government RPM, the manufacturer first sets the wholesale price for the retailer, the online price for the consumer, and the collection effort. After observing the manufacturer's wholesale price, the retailer sets the offline price. The profit functions of the dual-channel manufacturer and the offline retailer are as follows:

$$
\begin{aligned}
\pi_{m} & =\left(p_{1}-c\right) d_{1}+(w-c) d_{2}+s \tau\left(d_{1}+d_{2}\right)-\frac{1}{2} k \tau^{2}+m\left(\tau-\tau_{0}\right) \\
\pi_{r} & =\left(p_{2}-w\right) d_{2} .
\end{aligned}
$$

Using backward induction, we solve the model recursively based on their first-order condition. The optimal online price, online market volume, wholesale price, and collection rate of the dual-channel manufacturer as well as the offline retailing price are obtained and summarized in Proposition 1. All related proofs of Section 4 are put in Appendix A.

Proposition 1. We denote $\alpha_{0}$ the critical value of the consumer's loyalty to the online channel between the dual sales channel and single online sales channel of the manufacturer. When $0<\alpha<\alpha_{0}$, the manufacturer should sell products through dual channels. When $\alpha_{0}<\alpha<1$, the manufacturer should sell products only through the online channel, where $\alpha_{0}=\frac{2 k(a+c r)-2 m r s+a r s^{2}-(2 c k+s(-2 m+a s)) b_{1}}{2 a\left(k+r s^{2}-s^{2} b_{1}\right)}$. In this paper, we focus on the dual-channel supply chain under a government RPM to recycle used products. Therefore, we only provide the optimal decisions of the supply chain members as follows. 


$$
\begin{array}{r}
p_{1}^{*}=\frac{1}{4}\left(\frac{2 a(\alpha-1) r s^{2}-2 b_{1}(s(a(\alpha+1) s+4 m)-4 c k)}{b_{1}\left(-3 b_{1} s^{2}+4 k+2 r s^{2}\right)+r^{2} s^{2}}+\frac{(2 \alpha-1) a}{b_{1}+r}+\frac{a}{b_{1}-r}\right) \\
p_{2}^{*}=\frac{1}{4}\left(\frac{2 b_{1}(s(a(\alpha-2) s-2 m)+2 c k)-4 a \alpha k+4 a k-2 a \alpha r s^{2}+4 c k r-4 m r s}{b_{1}\left(-3 b_{1} s^{2}+4 k+2 r s^{2}\right)+r^{2} s^{2}}+\frac{a-2 a \alpha}{b_{1}+r}+\frac{a}{b_{1}-r}\right) \\
w^{*}=\frac{1}{4}\left(\frac{2 a(\alpha-1) r s^{2}-2 b_{1}(s(a(\alpha+1) s+4 m)-4 c k)}{b_{1}\left(-3 b_{1} s^{2}+4 k+2 r s^{2}\right)+r^{2} s^{2}}+\frac{a-2 a \alpha}{b_{1}+r}+\frac{a}{b_{1}-r}\right) \\
\tau^{*}=\frac{b_{1}\left(s(\alpha a+a+2 c r)-3 b_{1} c s+4 m\right)+r s(-\alpha a+a+c r)}{b_{1}\left(-3 b_{1} s^{2}+4 k+2 r s^{2}\right)+r^{2} s^{2}}
\end{array}
$$

In this section, we derive managerial insights by analyzing the optimal decisions of the supply chain members, which are shown in Proposition 1 . To guarantee the convexity of the optimization, $b_{1}\left(-3 b_{1} s^{2}+4 k+2 r s^{2}\right)+r^{2} s^{2}>0$ is required.

Proposition 2. We find that $\frac{\partial \alpha_{0}}{\partial m}>0$, which means that the critical value $\alpha_{0}$ increases in $m$.

Proposition 2 suggests that the government RPM can improve the robustness of the dual-channel supply chain by extending the upper bound of the consumer's preference for the direct sales channel. Moreover, the government improves the competitive advantage of the retailer channel.

Proposition 3. In the dual-channel supply chain, $\frac{\partial p_{1}^{*}}{\partial m}<0, \frac{\partial p_{2}^{*}}{\partial m}<0, \frac{\partial \tau^{*}}{\partial m}>0, \frac{\partial d_{1}^{*}}{\partial m}>0$, and $\frac{\partial d_{2}^{*}}{\partial m}>0$. The optimal online price and retailer price decrease in $m$. The optimal collection rate, online market demand, and offline market demand increase in $\mathrm{m}$.

Proposition 3 indicates that the government RPM scheme can effectively improve the collection rate of the used products from consumers. Meanwhile, with more residual value of the collected used products, the RPM scheme achieves the purpose of reducing unit production cost. The manufacturer enjoys a cost advantage in the forward channel, using a lower price to incentivize market demand of the new products both in the online and retail sales channels. Thus, the influence of government RPM on the reverse channel can improve the economic performance of the forward channel by moderating production cost.

In the following, we analyze the impact of the government RPM scheme on the manufacturer's profitability.

Proposition 4. There exists a critical value $m_{0}$ of the government RPM intensity of the manufacturer's profit. When $m<m_{0}$, the profit of the manufacturer decreases in $m$; when $m>m_{0}$, the profit of manufacturer increases in $m$. The value of $m_{0}$ is as follows.

$$
m_{0}=\frac{1}{4}\left(\frac{r s\left(a(\alpha-1)-c r+r s \tau_{0}\right)}{b_{1}}-a(\alpha+1) s+3 b_{1} s\left(c-s \tau_{0}\right)+2 r s\left(s \tau_{0}-c\right)+4 k \tau_{0}\right)
$$

From Proposition 4 , we find that $m_{0}$ is decided by $\tau_{0}$. The government financial intervention should not hurt manufacturers' profits. Thus, there exists a trade-off between this consideration and expenditure of the target collection rate of RPM. $\tau_{0} \leq 0$ must be satisfied in the consideration. Therefore, we can obtain the maximum and optimal $\tau_{0}^{*}$ through $\tau_{0}=0$. Interestingly, $\tau_{0}^{*}=\tau^{*}$, which indicates the number relationship between the optimal RPM parameter settings of the intensity and target collection rate. Thus, if we can get the optimal value of RPM intensity while maximizing the total social welfare, we can obtain the optimal target collection rate of the RPM. Based on this, we provide a method of optimizing the RPM scheme of the whole closed-loop supply chain system. 
Proposition 5. We find that $\frac{\partial \tau^{*}}{\partial \alpha}>0$, which indicates that the optimal collection rate of used products increases with $\alpha$, the consumers' loyalty to the online channel.

Proposition 5 indicates that the bigger the share of the online market, the higher the collection rate of the used products. In reality, the higher collection rate indicates the lower production cost with more residual value from the used products, which will also incur higher recycling cost. Meanwhile, without the retailer sharing the profit from selling new products, the manufacturer enjoys a more profitable operation structure in the online channel, which will increase the collection effort to further reduce production cost. Therefore, the effort in the reverse channel of the manufacturer will move into a more competitive direction of the forward channel.

\section{Optimal Government Policy for the RPM}

In this section, we further investigate how the government should design the RPM scheme including the intensity and the target quantity. While in reality, a government may have different goals when implementing financial intervention, thus we convert them into an index called total social welfare comprised of consumer surplus, supply chain profit, environmental impact and government expenditure.

\subsection{Social Welfare}

In this subsection, we assume that the government implements the RPM to maximize the total social welfare, which consists of consumer surplus, total profits of the supply chain system, environmental impact, and government RPM expenditure [27].

(1) Consumer surplus (CS): Consumer surplus is an economic indicator to measure the benefits from the consumers' perspective [28,29]. In the dual-channel supply chain, the total consumer surplus is divided into two parts: the online market and offline market consumer surplus. In the online channel, the largest online price is $\frac{a \alpha}{b_{1}}$, which is not disturbed by the retailer channel. The retailer is simply taking a share of the online market demand without affecting the highest online price accepted by consumers. From the perspective of online market segmentation, the online market demand $d_{1}$ is a linear function of $p_{1}$. Thus, we denote $C S_{1}$ as consumer surplus of the online market, where $C S_{1}=\frac{1}{2} d_{1}^{*}\left(\frac{a \alpha}{b_{1}}-p_{1}^{*}\right)$. Similarly, we denote $C S_{2}$ as consumer surplus of offline market, where $C S_{2}=\frac{1}{2} d_{2}^{*}\left(\frac{(1-\alpha) a}{b_{1}}-p_{2}^{*}\right)$. Therefore, the total consumer surplus of the dual channel supply chain, $C S$, can be calculated as follows:

$$
C S=C S_{1}+C S_{2}=\frac{1}{2} d_{1}^{*}\left(\frac{a \alpha}{b_{1}}-p_{1}^{*}+\frac{1}{2} d_{2}^{*}\left(\frac{(1-\alpha) a}{b_{1}}-p_{2}^{*}\right) .\right.
$$

In order to analyze the consumer surplus, we develop a numerical example with the data in Table 2, which describes the relationship between $m$, the intensity of the government RPM, and consumer surplus. From Figure 2, we can see that the consumer surplus is a monotonically increasing function of $m$.

Table 2. Parameter settings.

\begin{tabular}{cc}
\hline Parameters & Value \\
\hline$b_{1}$ & 2 \\
$r$ & 0.5 \\
$c$ & 50 \\
$s$ & 20 \\
$a$ & 200 \\
$k$ & 8000 \\
$\alpha$ & 0.5 \\
$e_{1}$ & 10 \\
\hline
\end{tabular}




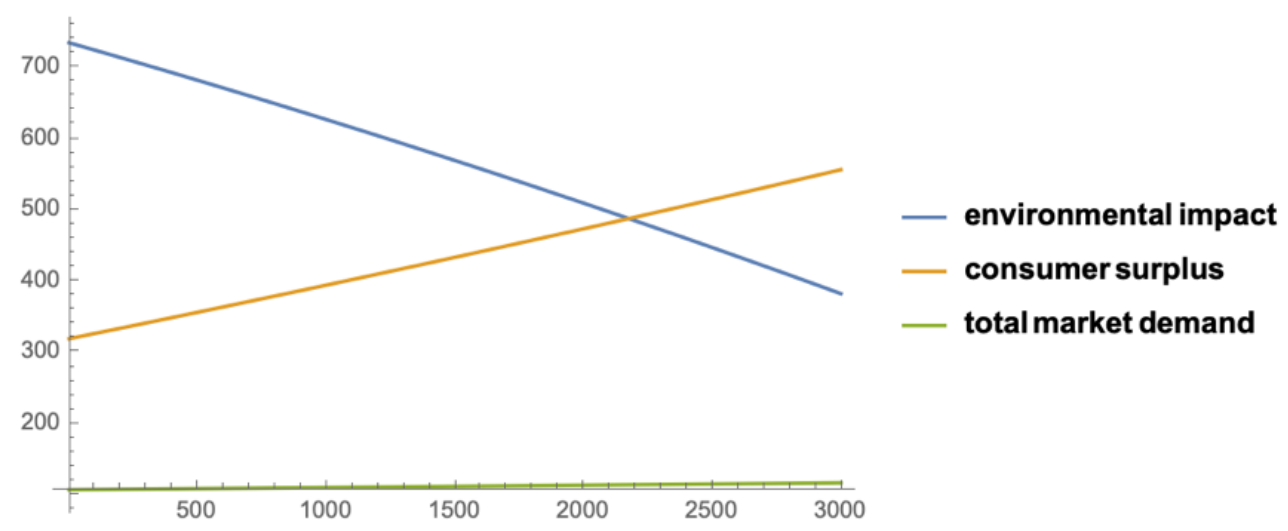

Figure 2. The consumer surplus, market demand, and environmental impact with respect to $m$.

(2) Total profit of the supply chain: The total profit is equal to the manufacturer's profit plus the retailer's profit, which can be formulated as follows.

$$
\pi=\pi_{m}^{*}+\pi_{r}^{*}
$$

We also investigate how the government affects the manufacturer's profit without RPM expenditure, as well as the retailer's profit. In order to visually describe the number relationship of the profits with respect to $m$, we develop a numerical example, as shown in Figure 3. We can obtain that the profit of the manufacturer without government RPM expenditure decreases with $m$, which indicates that the government RPM scheme incurs a higher collection cost. However, a higher collection rate will further decrease the production cost for the manufacturer, which will make the retailer enjoy lower wholesale. Thus, from Figure 3, the retailer's profit increases with $m$. Interestingly, the RPM expenditure scheme has two effects that are opposite to the operation performance of the manufacturer and retailer. In other words, the government RPM can improve the competitive advantage of the retailer and promote stability of dual-channel supply chain, which is consistent with Proposition 2.

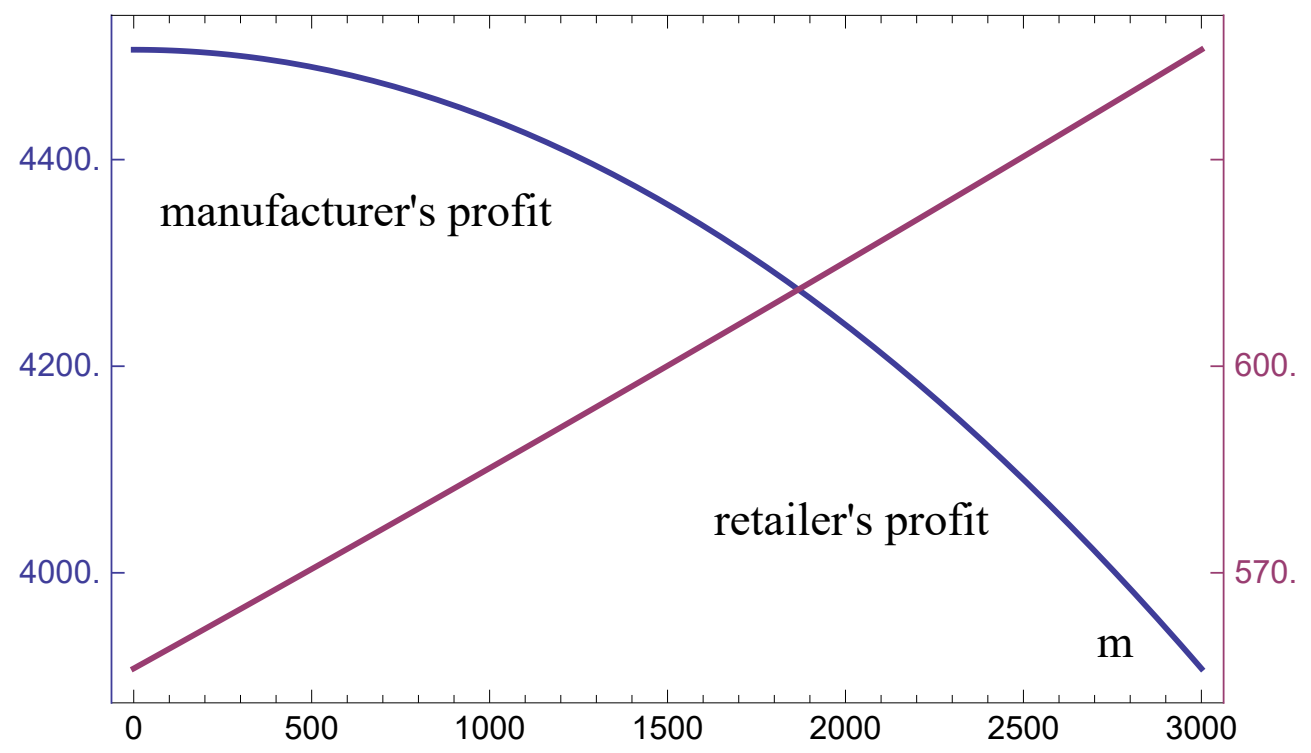

Figure 3. Profits of the supply chain members with respect to $m$.

(3) Environmental impact (E): Following [30], we convert the environmental impact into monetary terms. We use $e_{1}$, a general parameter including pollution as well as resource and energy savings, to denote the unit monetary environmental impact of new products because the manufacturer can extract valuable components from used products recycled from consumers, which will be thrown away 
to the environment through a strict disposal process. In order to simplify the model's parameters, we assume that the recycled products have no negative impacts on the environment. the environmental impact can be formulated as follows:

$$
E=e_{1}\left(d_{1}^{*}+d_{2}^{*}\right)\left(1-\tau^{*}\right)
$$

Through a numerical example, we further analyze how the intensity of the government RPM affects the total market demand and environmental impact, as shown in Figure 2. We can obtain that the total market demand increases with $m$ and the negative environmental impact decreases with $m$, which is induced by the higher collection rate of the used products encouraged by the government RPM scheme. Therefore, the government can improve market performance and decrease the environmental impact through the RPM scheme, which is what government financial intervention is all about.

(4) Government expenditure $(G)$ : The government designs the RPM for enterprises to protect the environment, which incentivizes the manufacturer to collect used products through financial intervention. From the public welfare perspective, the government is only concerned with overall externalities and government surplus. The government expenditure on RPM can be formulated as follows [25].

$$
G=m\left(\tau^{*}-\tau_{0}\right)
$$

Finally, the total social welfare is formulated as follows, which is consistent with the literature [31].

$$
S W=C S+\pi+E-G
$$

Before getting the optimal government RPM, we first analyze the optimal intensity of the RPM $m$ to maximize the performance of the total social welfare. Then, corresponding to Proposition 4, we can obtain the optimal target quantity of the RPM $\tau_{0}$ to maximize the profits of the system supply chain and the approximate government financial expenditure. Therefore, we can get the optimal RPM decision of the government.

\subsection{The Impact of Government RPM Intensity on Total Social Welfare}

In this subsection, we investigate the impact of government RPM intensity on the total social welfare. However, for the optimal $\mathrm{m}^{*}$, it is too difficult to get an analytical solution. Therefore, we use a numerical analysis to illustrate the existence and value of the optimal $m^{*}$. In addition, a sensitive analysis of the proposed model parameters is conducted. Meanwhile, we also investigate the models with different values of consumer loyalty to the online sales channel. The following parameter values are used for the analysis: $r=0.5, b_{1}=1, c=50, s=20, a=100, k=8000, e_{1}=10, a=400$, and $\alpha \in\{0.45,0.5,0.55\}$.

Figure 4 shows the change of total social welfare with respect to the government RPM intensity. We can see that the total social welfare is a concave function of $m$. Therefore, there exists an optimal $m^{*}$ to maximize the social welfare. The optimal $m^{*}$ means that the government RPM makes the optimal intensity decision for the supply chain system, environmental impact, consumer surplus, and the government expenditure. The interpretation of this finding is that the RPM promotes the increase of social welfare by collecting used products, such that the production cost of manufacturers proposed in Proposition 4 and environmental impact are decreased, while the intensity of the RPM increases first. However, when $m$ exceeds the peak of the curve, the RPM will not increase this effect. In addition, we also find that the consumer loyalty to the online channel will change the position of the extreme value of the curve, which contains the position of the $m^{*}$ and the maximum value of social welfare. In order to find out how the consumer loyalty affects the curve, we further study the relationships among the total social welfare, the intensity of the government RPM, and the consumer loyalty to the online channel using the above data. 


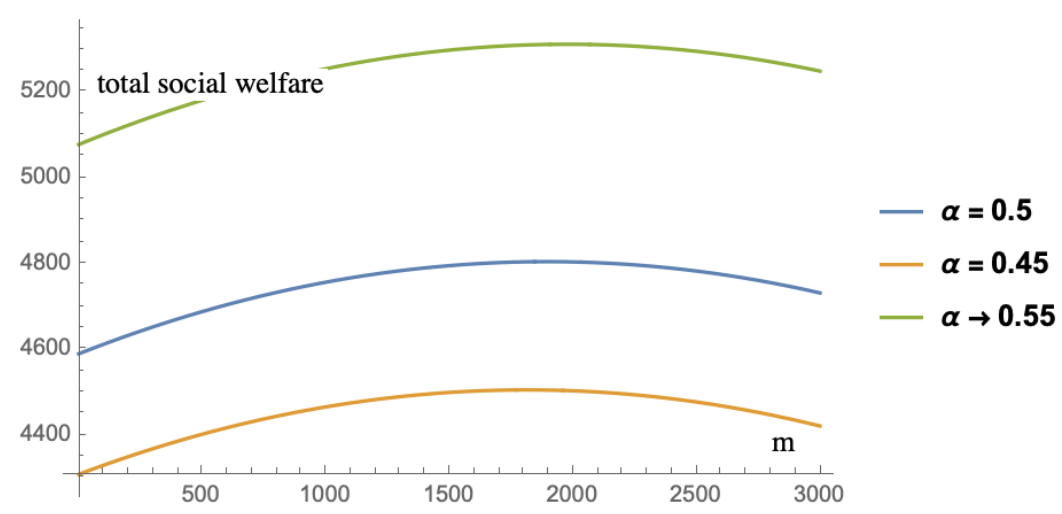

Figure 4. Total social welfare change according to RPM intensity.

It can be seen from Figure 5 that the value of $m^{*}$ decreases as $s$ increases, which means that when the consumers prefer to buy the products online more and more, the government can make the intensity of the RPM lower. In addition, the total social welfare falls as $s$ increases, which indicates that the online channel will bring lower social welfare and the dual channels will bring lower social welfare, which is caused by the competition and channel conflict.

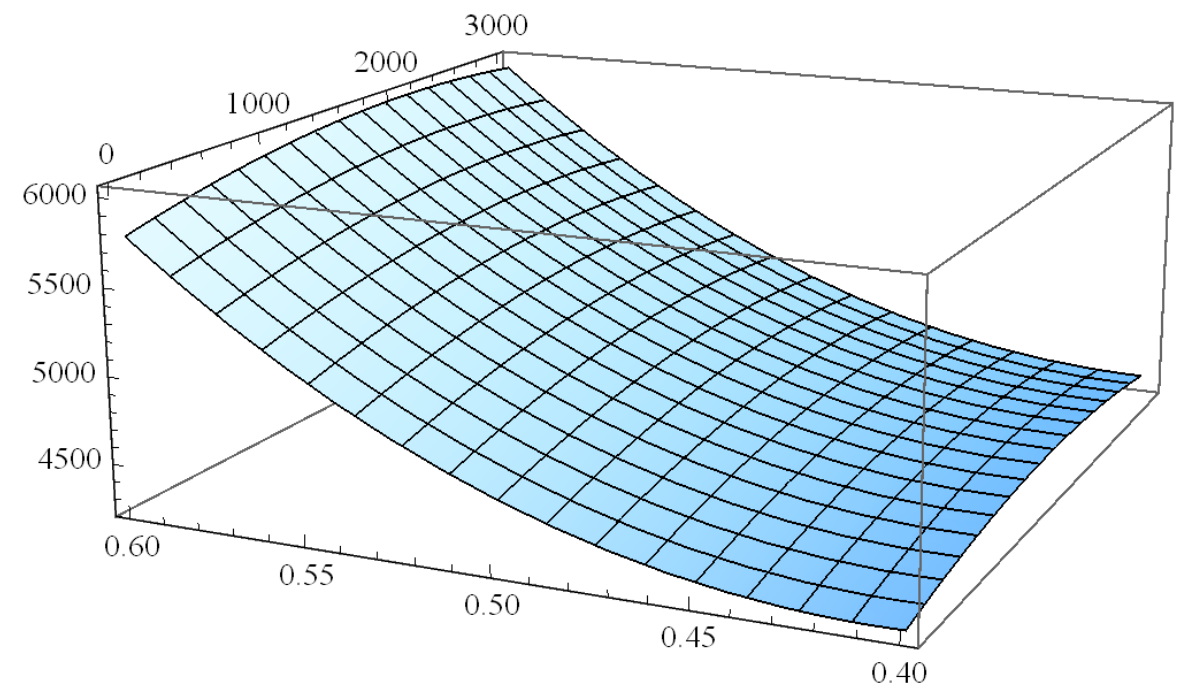

Figure 5. Total social welfare with respect to $m$ and $s$.

\section{Optimal Design of the RPM Scheme}

In this section, we show how the government should design the RPM scheme. From Section 5.2, we can determine the optimal $m^{*}$, where $\frac{\partial S W}{\partial m}\left(m^{*}\right)=0$, and the social welfare reaches the maximum value. Then, from Proposition $4, \tau_{0}^{*}=\tau^{*}$, so we can get the optimal $\tau_{0}^{*}$, the target collection rate of the government RPM. Therefore, we have achieved the optimal decision set, $\left(m^{*}, \tau_{0}^{*}\right)$. Under this condition, government financial intervention maximizes the social welfare and the profits of the supply chain system with approximate government expenditure.

In order to show the process of getting the optimal government RPM visually, we provide numerical examples with the parameters in Table 2. Through the numerical analysis, we get the government RPM with different consumer loyalty to the online channel, which is shown in Table 3. In addition, for the government's adoption of the optimal RPM to incentivize the enterprise to collect used products and maximize the total social welfare in the dual-channel CLSC, the optimal decisions and profits of the supply chain members are provided in Table 4. 
Table 3. The government optimal RPM.

\begin{tabular}{ccc}
\hline$s$ & $\boldsymbol{m}^{*}$ & $\boldsymbol{\tau}_{\mathbf{0}}^{*}$ \\
\hline 0.4 & 1732.47 & 0.481 \\
0.45 & 1813.91 & 0.502 \\
0.5 & 1895.34 & 0.523 \\
0.55 & 1976.78 & 0.543 \\
0.6 & 2058.22 & 0.564 \\
\hline
\end{tabular}

Table 4. The decisions and profits of supply chain members under the optimal government RPM.

\begin{tabular}{ccccccc}
\hline $\boldsymbol{s}$ & $\boldsymbol{p}_{\mathbf{1}}^{*}$ & $\boldsymbol{p}_{\mathbf{2}}^{*}$ & $\boldsymbol{w}^{*}$ & $\boldsymbol{\tau}^{*}$ & $\boldsymbol{\pi}_{\boldsymbol{m}}^{*}$ & $\boldsymbol{\pi}_{\boldsymbol{r}}^{*}$ \\
\hline 0.4 & 78.656 & 117.285 & 94.856 & 0.481 & 3862.56 & 1006.11 \\
0.45 & 82.648 & 110.655 & 90.648 & 0.502 & 4009.99 & 800.555 \\
0.5 & 86.440 & 104.025 & 86.440 & 0.523 & 4267.29 & 618.467 \\
0.55 & 90.232 & 97.395 & 82.232 & 0.543 & 4636.22 & 459.840 \\
0.6 & 94.023 & 90.765 & 78.023 & 0.564 & 5111.49 & 324.677 \\
\hline
\end{tabular}

\section{Conclusions and Future Research}

This paper establishes a closed-loop supply chain model considering the financial intervention of the government's RPM in the recycling activities of enterprises for the first time. We analyze the influence of the government's RPM on the optimal decisions of the members of the closed-loop supply chain and the two forward channels. We found that the government's RPM enhances the stability of the dual-channel supply chain and can increase the recovery rate. In addition, we provide an optimal RPM scheme for the government to maximize the social welfare of the whole supply chain system.

This paper has not only important theoretical significance, but also has important practical guidance. In the aspect of theory, this paper extends the research on closed-loop supply chain management. Previous studies mainly discussed the influence of government financial intervention on single-channel decision-making and social welfare. However, companies at the present stage have developed dual-channel sales of products. For example, Huawei has set up a Huawei mall to sell products online while entrusting offline retail-experience stores to sell products. In the Huawei mall, consumers can participate in recycling activities, such as a trade-in program. In fact, this business model has become widely adopted by electronic product enterprises. Therefore, it is necessary to study the efficiency of the government RPM in this business model and its impact on social welfare, and we find that the government can reduce the channel conflict between the manufacturer and the retailer by strengthening the profits of the reverse channel. Furthermore, we provide a method to achieve the optimal RPM scheme, where we first calculated the optimal RPM intensity using social welfare, and then derived the amount of recovery according to the intensity.

Our research is not exempt from limitations that require further investigation. First, we assume that all the players have full information, which is not the case in practice. Therefore, further study should explore the situation of information asymmetry among the supply chain members. Second, we assume that the demand function is deterministic. Considering the fuzziness, uncertainty, and quality sensitivity associated with market demand, uncertainty should be modeled in future research. Third, we assume that the recycled/remanufactured products have no difference from the new products with new materials, which could be relaxed to model consumers' different perceptions in future research.

Author Contributions: Conceptualization, H.C. and Z.D.; methodology, Z.D.; software, Z.D.; validation, G.L., H.C., and Z.D.; formal analysis, Z.D.; investigation, H.C.; resources, H.C.; data curation, G.L.; writing—original draft preparation, Z.D.; writing—review and editing, G.L.; visualization, Z.D.; supervision, H.C.; project administration, G.L. All authors have read and agreed to the published version of the manuscript.

Funding: This research receive no external funding.

Conflicts of Interest: The authors declare no conflict of interest. 


\section{Appendix A. Proof of Proposition 1}

In the Stackelberg game, the manufacturer is the CLSC leader. The online price $\left(p_{1}\right)$, the wholesale price $(w)$, and the collection rate $(\Gamma)$ are the manufacturer's decision variables. So, the manufacturer's objective function is

$$
\pi_{m}=\left(p_{1}-c\right) d_{1}+(w-c) d_{2}+s \tau\left(d_{1}+d_{2}\right)-\frac{1}{2} k \tau^{2}+m\left(\tau-\tau_{0}\right) .
$$

The retailer decides the offline price based on the manufacturer's decisions. The offline price $p_{2}$ is the retailer's decision variable, and its corresponding profit function is

$$
\pi_{r}=\left(p_{2}-w\right) d_{2}
$$

Using the method of backward induction, the solution order is opposite to the decision-making sequence. We first identify the optimal solution of the retailer's offline price $p_{2}$ from the first-order derivative.

$$
p_{2}=\frac{-\alpha a+a+b_{1} w+p_{1} r}{2 b_{1}}
$$

Substitute Equation (A3) into the manufacturer's objective function and then solve the function. We get the Hessian matrix of the manufacturer's objective function $A$. To ensure the function is concave, its Hessian matrix must be negative. There, the condition $b_{1}\left(-3 b_{1} s^{2}+4 k+2 r s^{2}\right)+r^{2} s^{2}>0$ must be satisfied. Based on this, we can obtain the $p_{1}^{*}, w^{*}, \tau^{*}$, and $p_{2}^{*}$ from the first-order derivative, which corresponds to Proposition 1 . In addition, we also discuss $d_{2}^{*}$ and $d_{1}^{*}$. From the optimal solutions of the manufacturer, we can obtain $d_{2}^{*}$ and $d_{1}^{*}$ as follows.

$$
\begin{gathered}
d_{2}^{*}=\frac{b_{1}\left(b_{1}(s(a(2 \alpha-1) s+2 m)-2 c k)+a\left((1-2 \alpha) r s^{2}-2(\alpha-1) k\right)+2 r(c k-m s)\right)}{4 b_{1}\left(2 k+r s^{2}\right)-6 b_{1}^{2} s^{2}+2 r^{2} s^{2}} \\
d_{1}^{*}=\frac{b_{1}\left(b_{1}(s(a(1-2 \alpha) s+4 m)-4 c k)+4 a \alpha k+a(2 \alpha-1) r s^{2}+2 c k r-2 m r s\right)+2 r(-a \alpha k+a k+c k r-m r s)}{2 b_{1}\left(-3 b_{1} s^{2}+4 k+2 r s^{2}\right)+2 r^{2} s^{2}}
\end{gathered}
$$

We denote $\alpha_{0}$ as the critical value of the consumers' loyalty to the online channel between the dual channels and the single retailer channel. When $\alpha_{0}<\alpha<1$, the manufacturer only has the online channel to sell the products; when $\alpha<\alpha_{0}$, the manufacturer owns two channels. Similarly, we denote $\alpha_{1}$ as the critical value of the consumers' loyalty between the online channel and the dual channels. When $\alpha<\alpha_{1}$, the manufacturer only has the retailer channel. We find that $\alpha_{1}=\frac{-a b_{1} r s^{2}+a b_{1}^{2} s^{2}+2 a k r+2 b_{1} c k r-4 b_{1}^{2} c k-2 b_{1} m r s+4 b_{1}^{2} m s+2 c k r^{2}-2 m r^{2} s}{2 a\left(-2 b_{1} k-b_{1} r s^{2}+b_{1}^{2} s^{2}+k r\right)}<0$ and $\alpha_{0}=\frac{-a b_{1} s^{2}+2 a k+a r s^{2}-2 b_{1} c k+2 b_{1} m s+2 c k r-2 m r s}{2 a\left(-b_{1} s^{2}+k+r s^{2}\right)}$, which indicates that there exists a critical value $\alpha_{0}$ between the single retailer channel and the dual channels. This paper focuses on the condition of a dual-channel supply chain; thus, we omit the discussions of the condition $\alpha_{0}<\alpha<1$.

\section{References}

1. Wang, W.B.; Zhang, Y.; Zhang, K.; Bai, T.; Shang, J. Reward-penalty mechanism for closed-loop supply chains under responsibility-sharing and different power structures. Int. J. Prod. Econ. 2015, 170, 178-190. [CrossRef]

2. Zhang, X.Q.; Su, Y.S.; Yuan, X.G. Government reward-penalty mechanism in closed-loop supply chain based on dynamics game theory. Discret. Dyn. Nat. Soc. 2018, 10.[CrossRef]

3. Wang, L.S.; Song, H.M.; Wang, Y.Z. Pricing and service decisions of complementary products in a dual-channel supply chain. Comput. Ind. Eng. 2017, 105, 223-233. [CrossRef]

4. Chiang, W.Y.K.; Chhajed, D.; Hess, J.D. Direct-marketing, indirect profits: A strategic analysis of dual-channel supply-chain design. Manag. Sci. 2003, 49, 1-20. [CrossRef]

5. Huang, W.; Swaminathan, J.M. Introduction of a second channel: Implications for pricing and profits. Eur. J. Oper. Res. 2009, 194, 258-279. [CrossRef] 
6. Tsay, A.A.; Agrawal, N. Channel conflict and coordination in the e-commerce age. Prod. Oper. Manag. 2004, 13, 93-110. [CrossRef]

7. Dumrongsiri, A.; Fan, M.; Jain, A.; Moinzadeh, K. A supply chain model with direct and retail channels. Eur. J. Oper. Res. 2008, 187, 691-718. [CrossRef]

8. Chen, J.; Zhang, H.; Sun, Y. Implementing coordination contracts in a manufacturer stackelberg dual-channel supply chain. Omega-Int. J. Manag. Sci. 2012, 40, 571-583. [CrossRef]

9. Xu, G.Y.; Dan, B.; Zhang, X.M.; Liu, C. Coordinating a dual-channel supply chain with risk-averse under a two-way revenue sharing contract. Int. J. Prod. Econ. 2014, 147, 171-179. [CrossRef]

10. Aksen, D.; Aras, N.; Karaarslan, A.G. Design and analysis of government subsidized collection systems for incentive-dependent returns. Int. J. Prod. Econ. 2009, 119, 308-327. [CrossRef]

11. Xiao, T.J.; Shi, J. Pricing and supply priority in a dual-channel supply chain. Eur. J. Oper. Res. 2016, 254, 813-823. [CrossRef]

12. Chen, J.X.; Liang, L.; Yao, D.Q.; Sun, S.N. Price and quality decisions in dual-channel supply chains. Eur. J. Oper. Res. 2017, 259, 935-948. [CrossRef]

13. Brandenburg, M.; Govindan, K.; Sarkis, J.; Seuring, S. Quantitative models for sustainable supply chain management: Developments and directions. Eur. J. Oper. Res. 2014, 233, 2. [CrossRef]

14. Savaskan, R.C.; Bhattacharya, S.; Van Wassenhove, L.N. Closed-loop supply chain models with product remanufacturing. Manag. Sci. 2004, 50, 239-252. [CrossRef]

15. Savaskan, R.C.; Van Wassenhove, L.N. Reverse channel design: The case of competing retailers. Manag. Sci. 2006, 52, 1-14. [CrossRef]

16. Ferrer, G.; Swaminathan, J.M. Managing new and remanufactured products. Manag. Sci. 2006, 52, 15-26. [CrossRef]

17. Saha, S.; Sarmah, S.P.; Moon, I. Dual channel closed-loop supply chain coordination with a reward-driven remanufacturing policy. Int. J. Prod. Res. 2016, 54, 1503-1517. [CrossRef]

18. Huang, M.; Song, M.; Lee, L.H.; Ching, W.K. Analysis for strategy of closed-loop supply chain with dual recycling channel. Int. J. Prod. Econ. 2013, 144, 510-520. [CrossRef]

19. Gao, J.H.; Han, H.S.; Hou, L.T.; Wang, H.Y. Pricing and effort decisions in a closed-loop supply chain under different channel power structures. J. Clean. Prod. 2016, 112, 2043-2057. [CrossRef]

20. Xie, J.P.; Zhang, W.S.; Liang, L.; Xia, Y.; Yin, J.; Yang, G. The revenue and cost sharing contract of pricing and servicing policies in a dual-channel closed-loop supply chain. J. Clean. Prod. 2018, 191, 361-383. [CrossRef]

21. De Giovanni, P.; Reddy, P.V.; Zaccour, G. Incentive strategies for an optimal recovery program in a closed-loop supply chain. Eur. J. Oper. Res. 2016, 249, 605-617. [CrossRef]

22. Liu, H.H.; Lei, M.; Deng, H.H.; Leong, G.K.; Huang, T. A dual channel, quality-based price competition model for the weee recycling market with government subsidy. Omega-Int. J. Manag. Sci. 2016, 59, $290-302$. [CrossRef]

23. Heydari, J.; Govindan, K.; Jafari, A. Reverse and closed loop supply chain coordination by government role. Transp. Res. Part D Transp. Environ. 2017, 52, 379-398. [CrossRef]

24. Ma, W.M.; Zhao, Z.; Ke, H. Dual-channel closed-loop supply chain with government consumption-subsidy. Eur. J. Oper. Res. 2013, 226, 221-227. [CrossRef]

25. Wang, W.B.; Zhou, S.Y.; Zhang, M.; Sun, H.; He, L.Y. A closed-loop supply chain with competitive dual collection channel under asymmetric information and reward-penalty mechanism. Sustainability 2019, 10, 31. [CrossRef]

26. Arshad, M.; Khalid, Q.S.; Lloret, J.; Leon, A. An efficient approach for coordination of dual-channel closed-loop supply chain management. Sustainability 2018, 10, 20. [CrossRef]

27. He, P.; He, Y.; Xu, H. Channel structure and pricing in a dual-channel closed-loop supply chain with government subsidy. Int. J. Prod. Econ. 2019, 213, 108-123. [CrossRef]

28. Cohen, M.C.; Lobel, R.; Perakis, G. The impact of demand uncertainty on consumer subsidies for green technology adoption. Manag. Sci. 2016, 62, 1235-1258. [CrossRef]

29. Jena, S.K.; Ghadge, A.; Sarmah, S.P. Managing channel profit and total surplus in a closed-loop supply chain network. J. Oper. Res. Soc. 2018, 69, 1345-1356. [CrossRef]

30. Sheu, J.B.; Chen, Y.M.J. Impact of government financial intervention on competition among green supply chains. Int. J. Prod. Econ. 2012, 138, 201-213. [CrossRef] 
31. Park, S.J.; Cachon, G.P.; Lai, G.M.; Seshadri, S. Supply chain design and carbon penalty: Monopoly vs. monopolistic competition. Prod. Oper. Manag. 2015, 24, 1494-1508.

Publisher's Note: MDPI stays neutral with regard to jurisdictional claims in published maps and institutional affiliations.

(C) 2020 by the authors. Licensee MDPI, Basel, Switzerland. This article is an open access article distributed under the terms and conditions of the Creative Commons Attribution (CC BY) license (http:/ / creativecommons.org/licenses/by/4.0/). 